\title{
SKIN CANCER PREVENTION AMONG SCHOOL CHILDREN: A BRIEF REVIEW
}

\author{
Vinayak K. Nahar \\ Department of Health, Exercise Science and Recreation Management, The University of Mississippi, Oxford, MS, USA
}

\begin{abstract}
SUMMARY
In many countries the incidence of melanoma has been doubling in every 10 years. Since 1930, the rate of melanoma has increased over $1,800 \%$ and researchers are expecting this trend to continue and increase for the next 10 to 20 years. Primary prevention and early detection of skin cancer in childhood is important to reduce the risk of developing skin cancer later in life. Primary prevention programmes are more beneficial and effective in children, not only due to the particular importance of sunlight exposure during this period, but because this is when individuals are more open to changes and adopt new attitudes and behaviour. The purpose of this manuscript is to review the results of intervention studies designed to modify sun exposure behaviour among children in the United States of America, Australia and Europe. An additional purpose is to summarize the recommendations obtained from the reviewed studies. The strongest recommendation to emerge from this review is that the skin cancer primary prevention programme should be carried out over several school years, not just one time, to produce changes in the sun safety behaviour. Moreover, it recommends that parents should be targeted to educate their children about sun protective skills and promote skin cancer prevention behaviour.
\end{abstract}

Key words: skin cancer, primary skin cancer prevention, sun protection behaviour, school children

Address for correspondence: V. K. Nahar, Department of Health, Exercise Science and Recreation Management, The University of Mississippi, 215 Turner Center, P.O.Box 1848, Oxford, MS 38677, USA. Email: vknahar@go.olemiss.edu

\section{INTRODUCTION}

The human body is made up of different types of cells. Normally, these cells grow and divide in a regular order. This process is known as a cell cycle. Any kind of improper functioning in the cell cycle components may lead to tumor formation. Not all tumors are cancerous. There are two basic types of tumors. One type of tumor is benign (non-cancerous), the other type is malignant (cancerous) (1).

Skin is the largest organ of the human body (2). It has three main layers: the outer layer - epidermis, the inner layer-dermis and the lowermost tissue layer known as tela subcutanea. There are many types of epidermal cells - keratinocytes (some subtypes of them are basal cells and squamous cells), melanocytes, Langerhans dendritic cells, Merkel cells, and other infiltrating cells (lymphocytes, neutrophils, etc.). The three main types of skin cancer are named after these cells: basal cell carcinoma, squamous cell carcinoma, and melanoma (1). Of these three cancers, melanoma is the most serious type of skin cancer (3). Melanoma occurs when melanocytes become malignant. Melanocytes are located in the bottom part of epidermis and they produce melanin, the pigment responsible for the skin colour. When our body is exposed to ultra violet radiation (UVR) (the radiation can be either artificial - tanning bed, or natural - sunlight) melanocytes start producing more melanin and it leads to the tanning and darkening of the skin. Excessive exposure to UVR causes damage of melanocytes and increases the risk of skin cancer $(1,4)$. Skin cancers that are not cancerous are known as non-melanoma skin cancers, which comprised basal cell carcinoma and squamous cell carcinoma (5).

In many countries the incidence of melanoma has been doubling in every 10 years. Since 1930, the rate of melanoma has increased over $1,800 \%$ and researchers are expecting this trend to continue and rise for the next 10 to 20 years (6). The rapid increase in the incidence of skin cancer is believed to be caused by a marked increase in UVR on our planet due to ozone layer depletion $(7,8)$. Moreover, outdoor leisure, sunbathing behaviours, rise in use of sunbeds, and wearing clothes that do not protect skin from sun also play an important role in the increased rate of skin cancer (9-13). The other factors not depending on UVR exposure could be increased public awareness about skin cancer, increased life expectancy and improved diagnostic methods (14-17).

\section{Skin Cancer in Europe and Australia}

According to Cancer Research UK, in 2012 there were 12,818 new cases and 2,746 total deaths from melanoma in Britain (18). During the past 20 years the incidence of malignant melanoma has grown in Sweden with an average annual increase of $3.8 \%$ for men and $2.8 \%$ for women. Every year approximately 30,000 people in Sweden are diagnosed with skin cancer and approximately 400 die of skin cancer (19). Of 27 European Union countries, the highest incidence rates are estimated to be in Sweden for males (nearly 22 cases per 100,000) and Denmark for females (about 26 cases per 100,000), and the lowest rates are estimated to be in Greece for both genders (more than 3 male cases per 100,000, and approximately 3 female cases per 100,000) (18). Australia has the greatest incidence of skin cancer in the world and yearly incidence of skin cancer cases has recently been estimated to be over 700,000 (20). Moreover, about two in three Australians are likely to develop skin cancer before the age of 70 (21). In Australia, 10,342 new cases of melanoma were reported in 2007 alone, responsible for 1,279 deaths in the same year (21). 


\section{Skin Cancer in the United States of America}

In recent decades, in order to reduce potential exposure to UVR many national foundations and public health organizations including the Centers for Disease Control and Prevention (CDC), the American Academy of Dermatology (AAD), the American Cancer Society (ACS), and the Skin Cancer Foundation have worked closely to promote anti-skin cancer campaigns, raise awareness about dangers of UVR from both natural and artificial sources, and deliver educational programmes focusing on skin cancer prevention as well as the need to practice sun-safety behaviour. Despite efforts of providing vital sun protection information to the public, the incidence of skin cancer is increasing rapidly in the US, predominantly among white Americans and the projections suggest that this trend will continue (22-26).

Skin cancer is the most common form of cancer in the US (27). The incidence of skin cancer is growing more rapidly than incidence of all other cancers combined (i.e. breast, prostate, lung, and colon cancer) (2). It was estimated that one in five Americans will be diagnosed with skin cancer during his/her life (28). In the US, since 1973, new cases of melanoma and melanoma deaths have increased approximately by $150 \%$ and $44 \%$, respectively (29). In white skinned population, strong evidence of positive association between sun exposure, sunburn and melanoma risk was observed $(4,30-32)$. The rate of melanoma in white skinned population is higher than in any other race in the US. White people were more likely to die of melanoma of the skin than people of any other group. Hispanic people had the second highest rate of deaths from melanoma of the skin, followed by African Americans. Additionally, in males, melanoma is the fifth most common cancer and in females, it is the sixth most common cancer (29). According to ACS, in 2012, 44,250 new cases of melanoma in men and 32,000 cases in women will be diagnosed in the US, which will result in death of 6,060 men and 3,120 women (2).

\section{Skin Cancer Risk Factors}

Most skin cancers are caused by a long-term exposure to the sun $(33,34)$. Therefore, people who spent significant amount of time outdoor are more likely to have skin cancer - for example, farmers and construction site workers $(35,36)$. Moreover, fairskinned individuals who sunburn easily are at a higher risk for developing skin cancer than dark skinned people, since their skin produces less amount of the protective pigment called melanin (1). Family history of skin cancer can increase the risk of skin cancer (2). If one of your parents or a sibling has had skin cancer, you may be at increased risk of the disease (36). Furthermore, history of severe sunburns put individuals at risk of skin cancer (2). A person's risk for melanoma doubles if he or she has had five or more sunburns at any age (37). Changes in the surface of a mole such as scaliness, oozing, bleeding particularly in an adult age indicates the development of skin cancer (2). Sunbathing and tanning are also risk factors for skin cancer (38). Many people believe that suntanned skin will make them look attractive. Each year roughly 30 million population of the US use indoor tanning beds (39). Of the population using tanning beds, $2-3$ millions are teens (40). Additionally, frequent tanners are 2.5 times and 1.5 times more likely to develop squamous cell carcinoma and basal cell carcinoma, respectively (41). Furthermore, other risk factors include atypical (familiar) mole syndrome, defects of p16, p53 genes, exposition to chemicals (arsenic, chlorine, coal tar, etc.), and defects of DNA enzymes (xeroderma pigmentosum) (42).

\section{Skin Cancer Prevention}

There are three types of preventions: primary, secondary, and tertiary prevention. Primary prevention includes strategies that aim at lessening the risk factors of skin cancer, primarily exposure to sun rays and sunburn (43-46). The majority of skin cancer can be prevented by avoiding exposure to $\operatorname{UVR}(33,34)$. CDC recommended following key actions which people should adopt to protect their skin against UVR. People should try to stay in shade or limit their exposure to sun during 10 am to $4 \mathrm{pm}$. Always cover skin with a T-shirt, wide brimmed hat and wear sunglasses to protect eyes from sun especially when the sun is strong between $11 \mathrm{am}$ to $1 \mathrm{pm}$. Additionally, $99 \%$ of UVR can be blocked by using sunglasses (47). Sunscreen use is one of the most common protective behaviours for the prevention against skin cancer. Using sunscreen with a sun protection factor (SPF) of at least 15 reduces the risk of non-melanoma skin cancer (31). It was estimated that regular use of sunscreen with SPF of 15 for the first 18 years of life could reduce skin cancer by $78 \%$ (48).

Next, secondary prevention comprised screening that helps in finding skin cancer at an early stage. When abnormal tissue or cancer is found early, it may be easier to treat. Most of the skin cancers can be cured if detected early (2). The most important activity for secondary skin cancer prevention is self-examination of skin every month or assisted by second person (e.g. friend or spouse) (49). The screening by general practitioners or dermatologist is recommended as a second line examination. Skin cancer screening can be done by primary-care physicians or dermatologists in their offices, or through community-wide screening programmes (50).

Finally, tertiary prevention focuses on advance surgical methods, latest medicines and regular screening to prevent skin cancer occurrence again in those patients who already have history of skin cancer $(29,51)$.

\section{PURPOSE OF THE LITERATURE REVIEW}

In many countries programmes designed to reduce the incidence of skin cancer by altering sun exposure behaviour have been given high priority, while many studies have examined the resultant change in the knowledge level and attitudes towards skin cancer related health behaviour. The purpose of this manuscript is to review the results of intervention studies designed to modify sun exposure behaviour among children in the United States of America, Australia and Europe. An additional purpose is to summarize the recommendations obtained from the reviewed studies.

\section{METHODS OF LITERATURE SEARCH AND SELEC- TION CRITERIA}

To search articles concerned with the skin cancer prevention behaviour, literature search in the following databases was performed: EBSCO, PubMed and MEDLINE. The following keywords and phrases were used to search the articles in the databases: "skin cancer," "melanoma," "sun protection," "sun exposure," 
"sun behaviour," and "skin cancer intervention programmes."

The CDC, ACS, and the Melanoma Foundation of Australia websites were also used to find skin cancer statistics. The reference lists of all articles identified were examined for potentially relevant articles. The criteria used for the articles can be found in Table 1. The articles that met the criteria were then reviewed and summarized.

\section{REVIEW OF PUBLISHED STUDIES}

Girgis et al. compared methods of delivering an intervention programme in primary schools in Australia (52). In this randomized controlled trial they compared two types of intervention designed to improve sun protection behaviour in children aged 9-11 years. An intensive intervention programme Skin Safe was implemented over a 4-week period. The aim of the Skin Safe programme was to improve knowledge and attitudes about skin cancer and developing sun protection behaviour. Lecture was delivered from a Cancer Council Education Officer, posters and sunscreen samples were distributed at the end of the lecture. A total of 612 students participated in the study and then the students were randomly divided into three different groups: intensive intervention, standard intervention and control group. Questionnaires were distributed to collect data regarding knowledge and attitudes, and a self-completed diary was used to collect information regarding behaviour over five consecutive days (Monday-Friday). The Skin Safe programme was evaluated using pretest and posttest design. Results showed that students in the intensive intervention group were significantly more likely to use high level of protection at both posttest periods than control and standard intervention groups.

In the pre- and post- campaign questionnaire survey aimed at primary school children, Bastuji-Garin et al. assessed the impact of educational campaign on children's knowledge, attitude and sun exposure behaviour (53). The pre-campaign survey was undertaken in September 1991, using 228 children from primary schools in the following area of France: Paris, a suburb of Paris, Tours, and Marseille. School children were interviewed separately at school with a structured standardized questionnaire. After 9 months, in June 1992 before summer holidays, 228 primary school students participated in the educational programme at their schools. The educational programme was presented as a game during a 4-week period. The main objective of the educational programme was to make students aware of dangers of sun exposure. Then, 3 months later, after summer holidays, the post-campaign survey was undertaken in September 1992 on the same 228 students. The same person interviewed children both

Table 1. Study inclusion criteria

\begin{tabular}{|l|l|}
\hline Category & Criteria \\
\hline Time period & Publication date from 1990 to 2012 \\
\hline Study population & Children \\
\hline Location of the study & United States of America, Australia, Europe \\
\hline Publication language & English \\
\hline Study design & Randomized control trial or nonrandomized \\
\hline Intervention type & Skin cancer related prevention behaviour \\
\hline
\end{tabular}

years. The questionnaire consisted of questions regarding the children's colour of eyes and hair, skin type, ability to tan, attitude towards sun, knowledge about sun, protective measures, and the risk for skin cancer. Results from the two surveys revealed that children wore a hat and used sunscreen more frequently in postcampaign period (September 1992) but did not wear a T-shirt more frequently. Furthermore, after the post-campaign period school children often used protective sunscreens. Moreover, significantly greater amount of children avoided going outside especially when the sun was strong. Fewer cases of erythema were observed in the children. Also, a significantly greater proportion of children declared that all sunscreens did not provide equivalent sun protection and thought that the protection of shade or a T-shirt was more effective than the protection of sunscreen.

Targeting children in the kindergarten, Buller et al. examined the effect of the Sunny Days, Healthy Ways sun safety curriculum (SDHW) for children in kindergarten through fifth grade in Tucson, Arizona (54). SDHW was conducted with 744 students in 77 kindergartens to fifth grade classes in 10 elementary schools. The objective of SDHW was to increase student's knowledge, teach them solar protection skills, produce positive changes in attitudes, and stimulate sun safety behaviour. Students were divided into three groups. Group A students received SDHW twice over two years and group B received SDHW only once in a single year and group C (controlled group) students did not receive SDHW. Group C students only completed pretest and posttest surveys. The pretest and posttest surveys for school children were performed to measure change in children's sun safety knowledge, attitude and behaviour towards sun. The children's skin tone was measured at pretest and posttest using a colorimeter. Results from the pretest and posttest were following: Group A students who received SDHW twice over two years showed increased self-reported sun protection and decreased skin darkening. Group B students who received SDHW only once in a single year showed improved sun safety knowledge and group C (controlled group) students who did not receive SDHW showed no improvement in knowledge and skin darkening.

Buller et al. conducted a research to determine the effect of the Sunny Days, Healthy Ways sun safety curriculum (SDHW) on students in grades 6-8 (55). Two thousand thirty eight children participated from 30 middle schools in Colorado, New Mexico and Arizona. A group-randomized pretest-posttest controlled trial was undertaken to evaluate SDHW with children enrolled in grades 6-8. The SDHW curriculum had six 50-minute lessons intended to increase perceived personal risk for skin damage and skin cancer, positive outcome expectations about sun protection to reduce personal risk, and self-efficacy expectations for performing sun protection in a variety of situations. Moreover, SDHW taught children key prevention skills like selecting and applying sunscreen, selecting sun protective clothing, hats and sunglasses, using shade, and limiting time in the sun. Students were pretested in their classrooms in a group setting in February and March by trained staff. Students were then posttested at the end of the school year in May, using the same procedures as in pretesting. The surveys contained a variety of self-report measures on sun protection. In addition to this, skin tone of the children was assessed using colorimeter. Results of the pretest and posttest are following: compared to control schools, children receiving SDHW reported more frequent sun protection, a greater 
proportion of students wore long-sleeved shirts during recess and a significant greater proportion of students applied sunscreen. Students who had received SDHW improved their knowledge, decreased perceived barriers to using sunscreen, enhanced their self-efficacy expectations about sun safety, and also reduced favourable attitudes toward sun tanning.

Buendia-Eisman et al. evaluated school intervention programme to modify sun exposure behaviour in secondary education schools in Granada city, Spain (56). Group of 628 students from various schools in Granada participated in the study. Researchers implemented and assessed the school intervention programme to raise awareness and modify wrong behaviour regarding sunlight exposure. The following educational materials were used in the intervention: series of slides about sun, its nature, dangers, and benefits. Moreover, educational video, work material with games and a puzzle on the subjects about behaviour regarding the sun was provided. The control and study group completed a questionnaire prior to the intervention with educational programme and thereafter. Questionnaire contained knowledge about sun, skin, environment, health, behaviour and attitude about sun protection. Following results were obtained after the intervention: significant improvement in results concerning knowledge about sun exposure and skin as well as in attitudes and healthy behaviour regarding sun exposure.

Gilaberte et al. conducted a study to evaluate the effect of the Spanish school-based sun protection programme SolSano on student's knowledge, attitudes and practices about sun safety (57). A total of 5,845 children participated in the study. This was a non-randomized study without control group. SolSano - a school-based health programme was carried out in primary school, grades 1 and 2 (children aged 6-8 years). The aim of the SolSano programme was to increase children's knowledge and gain attitudes and skills required to reduce harmful effects of sun exposure and, in consequence, to prevent skin cancer. The SolSano programme contained educational material given to children and their parents. The educational material contained activity guide for teachers, a workbook for each pupil, and a poster with recommendations about how to behave in the sun. The SolSano programme was evaluated using pretest and posttest design. Knowledge and behaviour related to sun exposure were analyzed through pretest and posttest design. Results of the pretest and posttest are following: significant increase in the knowledge towards the use of sunscreen, significantly greater amount of children avoided going outside especially when the sun was strong. Additionally, there was a slight reduction in the percentage of students who desired to be tan.

\section{DISCUSSION}

Most of the studies to date have been pre-post intervention surveys designed to assess the impact of educational intervention programme on student's knowledge, attitudes and practices about sun safety.

The most successful school-based intervention is reported by Girgis et al. using the Skin Safe programme (52). The Skin Safe programme was designed to be implemented over a 4 weeks period within the normal school curriculum, which provided opportunities for cooperative learning techniques, student participation and problem based learning strategies in order to promote awareness of the problems and potential solutions associated with sun exposure. Post test results taken after 8 months following the end of the programme showed the significant increase in the protective behaviour which illustrates the success of this Skin Safe programme. However, the school-based programme targeting the same age group as the Skin Safe programme (Bastuji-Garin et al.) implemented over 4 weeks did not show consistent behaviour changes (53).

Results from a broader based campaign were reported by Buller et al. in 2,038 children from 30 middle schools in Colorado, New Mexico and Arizona. The research was conducted to determine effect of SDHW on students in grades 6-8 (55). In this study larger number of students dropped out of the SDHW intervention and results showed relatively small effects of SDHW in grades 6-8.

In contrast, another research was conducted targeting children in kindergartens in Tucson, Arizona. Buller and colleagues examined the effect of SDHW for children in kindergartens through fifth grade (54). SDHW was conducted with 744 students in 77 kindergartens to fifth grade classes in 10 elementary schools. And the results showed that continuing sun safety education is essential for achieving improvements among children in grades $2-5$. Moreover, results showed that direct education of very young children may not be very beneficial.

Evidence suggests that childhood and adolescence are critical periods in the etiology of skin cancer. Therefore, there is a strong need to develop primary prevention programmes that directly target school children. Primary prevention programmes are more beneficial and effective in children, not only due to the particular importance of sunlight exposure during this period, but because this is when individuals are more open to changes and adopt new attitude and behaviour. Also, during this period children are more receptive to new information (56). Moreover, the systematic evaluation of primary prevention programmes is necessary to develop a well designed educational programme which motivates people to acquire significant knowledge regarding the sun protection behaviour (57).

The skin cancer primary prevention programme should aim at consolidating knowledge and changing behaviour. In addition to this, the skin cancer primary prevention programme should emphasize the risks of intermittent sunlight exposure and how to use different sun protection methods (56). Furthermore, the skin cancer primary prevention programme should be run over several school years, not just one time, to produce changes in the sun safety behaviour (54)

Parents should be targeted to educate their children about sun protective skills and promote skin cancer prevention behaviour. Health care providers, including general practitioners and early childhood nurses, can play a vital role in educating parents about the importance to protect their children from excess sun exposure and increase their knowledge about skin cancer (52).

\section{REFERENCES}

1. National Cancer Institute. What you need to know about melanoma and other skin cancers [Internet]. Rockville: National Cancer Institute; 2010 [cited 2012 Nov 22]. Available from: http://www.cancer.gov/cancertopics/ wyntk/skin.pdf.

2. American Cancer Society. Melanoma skin cancer overview [Internet]. Atlanta: American Cancer Society; 2012 [cited 2012 Nov 22]. 
Available from: http://www.cancer.org/acs/groups/cid/documents/ webcontent/003063-pdf.pdf.

3. Jemal A, Siegel R, Xu J, Ward E. Cancer statistics, 2010. CA Cancer J Clin. 2010 Sep-Oct;60(5):277-300. Erratum in: CA Cancer J Clin. 2011 Mar-Apr;61(2):133-4

4. Brenner M, Hearing VJ. The protective role of melanin against UV damage in human skin. Photochem Photobiol. 2008 May-Jun;84(3):539-49.

5. Woolley T, Buettner PG, Lowe J. Sun-related behaviors of outdoor working men with a history of non-melanoma skin cancer. J Occup Environ Med. 2002 Sep;44(9):847-54.

6. Rigel DS, Friedman RJ, Kopf AW. The incidence of malignant melanoma in the United States: issues as we approach the 21st century. J Am Acad Dermatol. 1996 May;34(5 Pt 1):839-47.

7. Geller AC, Annas GD. Epidemiology of melanoma and nonmelanoma skin cancer. Semin Oncol Nurs. 2003 Feb;19(1):2-11.

8. Pons M, Quintanilla M. Molecular biology of malignant melanoma and other cutaneous tumors. Clin Transl Oncol. 2006 Jul;8(7):466-74.

9. Gilchrest BA, Eller MS, Geller AC, Yaar M. The pathogenesis of melanoma induced by ultraviolet radiation. N Engl J Med. 1999 Apr 29;340(17):1341-8

10. Lim P, Paver R, Peñas PF. Mohs micrographic surgery at the Skin and Cancer Foundation Australia, 10 years later (1997 vs 2007). J Am Acad Dermatol. 2010 Nov;63(5):832-5.

11. Preston DS, Stern RS. Nonmelanoma cancers of the skin. N Engl J Med. 1992 Dec 3;327(23):1649-62.

12. Welch HG, Woloshin S, Schwartz LM. Skin biopsy rates and incidence of melanoma: population based ecological study. BMJ. 2005 Sep 3;331(7515):481-4

13. From Australia to Brazil: sun worshippers beware. Bull World Health Organ [Internet]. 2009 [cited 2012 Nov 22];87(8):574-6. Available from: http://www.who.int/bulletin/volumes/87/8/09-030809.pdf.

14. Berwick M, Wiggins $C$. The current epidemiology of cutaneous malignant melanoma. Front Biosci. 2006 May 1;11:1244-54.

15. Linos E, Swetter SM, Cockburn MG, Colditz GA, Clarke CA. Increasing burden of melanoma in the United States. J Invest Dermatol. 2009 Jul;129(7):1666-74.

16. Purdue MP, Freeman LE, Anderson WF, Tucker MA. Recent trends in incidence of cutaneous melanoma among US Caucasian young adults. J Invest Dermatol. 2008 Dec;128(12):2905-8.

17. Talalay P, Fahey JW, Healy ZR, Wehage SL, Benedict AL, Min C, et al. Sulforaphane mobilizes cellular defenses that protect skin against damage by UV radiation. Proc Natl Acad Sci U S A. 2007 Oct 30;104(44):17500-5.

18. Cancer Research UK. Skin research statistics [Internet]. London: Cancer Research UK [cited 2012 Nov 22]. Available from: http://www.cancerresearchuk.org/cancer-info/cancerstats/types/skin/.

19. Bränström R, Brandberg Y, Holm L, Sjöberg L, Ullén H. Beliefs, knowledge and attitudes as predictors of sunbathing habits and use of sun protection among Swedish adolescents. Eur J Cancer Prev. 2001 Aug;10(4):337-45.

20. Cancer Council Act. Skin cancer in Australia [Internet]. Canberra: Cancer Council Act; 2007 [cited 2013 Mar 9]. Available from: http://www. actcancer.org/sun-smart/skin-cancer.aspx.

21. Australian Government, Department of Health and Aging. Key statistics. Key statistics of incidence and mortality of skin cancer in Australia [Internet]. Commonwealth of Australia; c2002 [cited 2013 Sep 5]. Available from: http://www.skincancer.gov.au/internet/skincancer/publishing.nsf/ Content/fact-2.

22. Goldberg MS, Doucette JT, Lim HW, Spencer J, Carucci JA, Rigel DS Risk factors for presumptive melanoma in skin cancer screening: American Academy of Dermatology National Melanoma/Skin Cancer Screening Program experience 2001-2005. J Am Acad Dermatol. 2007 Jul;57(1):60-6.

23. Harris RB, Alberts DS. Strategies for skin cancer prevention. Int J Dermatol. 2004 Apr;43(4):243-51.

24. Landis SH, Murray T, Bolden S, Wingo PA. Cancer statistics, 1998. CA Cancer J Clin. 1998 Jan-Feb;48(1):6-29. Erratum in: CA Cancer J Clin 1998 May-Jun;48(3):192. CA Cancer J Clin 1998 Nov-Dec;48(6):329.

25. Lu B, Makhija SK, Nettelbeck DM, Rivera AA, Wang M, Komarova S, et al. Evaluation of tumor-specific promoter activities in melanoma. Gene Ther. 2005 Feb;12(4):330-8.

26. Olson AL, Gaffney C, Starr P, Gibson JJ, Cole BF, Dietrich AJ. SunSafe in the Middle School Years: a community-wide intervention to change early-adolescent sun protection. Pediatrics. 2007 Jan;119(1):e247-56.

27. Rogers HW, Weinstock MA, Harris AR, Hinckley MR, Feldman SR, Fleischer AB, et al. Incidence estimate of nonmelanoma skin cancer in the United States, 2006. Arch Dermatol. 2010 Mar;146(3):283-7.
28. Robinson JK. Sun exposure, sun protection, and vitamin D. JAMA. 2005 Sep 28;294(12):1541-3.

29. CDC: EXCITE [Internet]. Atlanta: Centers for Disease Control and Prevention; 2008. Skin Cancer Module: practice exercises; $2007 \mathrm{Apr}$ 24 [cited 2012 Nov 22]. Available from: http://www.cdc.gov/excite/ skincancer/mod13.htm.

30. Callister P, Galtry J, Didham R. The risks and benefits of sun exposure: should skin colour or ethnicity be the main variable for communicating health promotion messages in New Zealand? Ethn Health. 2011 Feb;16(1):57-71

31. Solar and ultraviolet radiation. IARC Monogr Eval Carcinog Risks Hum. 1992;55:1-316.

32. Skin Cancer Foundation. Skin cancer and skin of color [Internet]. New York: Skin Cancer Foundation [cited 2012 Nov 20]. Available from: http://www.skincancer.org/prevention/skin-cancer-and-skin-of-color.

33. Armstrong BK, Kricker A. The epidemiology of UV induced skin cancer. J Photochem Photobiol B. 2001 Oct;63(1-3):8-18.

34. Glanz K, Lew RA, Song V, Murakami-Akatsuka L. Skin cancer prevention in outdoor recreation settings: effects of the Hawaii SunSmart Program. Eff Clin Pract. 2000 Mar-Apr;3(2):53-61.

35. Pichon LC, Mayer JA, Slymen DJ, Elder JP, Lewis EC, Galindo GR. Ethnoracial differences among outdoor workers in key sun-safety behaviors. Am J Prev Med. 2005 May;28(4):374-8.

36. Goldstein AM, Tucker MA. Genetic epidemiology of familial melanoma. Dermatol Clin. 1995 Jul;13(3):605-12.

37. Pfahlberg A, Kölmel KF, Gefeller O; Febim Study Group. Timing of excessive ultraviolet radiation and melanoma: epidemiology does not support the existence of a critical period of high susceptibility to solar ultraviolet radiation-induced melanoma. Br J Dermatol. 2001;144(3):4715.

38. El Ghissassi F, Baan R, Straif K, Grosse Y, Secretan B, Bouvard V, et al.; WHO International Agency for Research on Cancer Monograph Working Group. A review of human carcinogens - part D: radiation. Lancet Oncol. 2009 Aug; 10(8):751-2

39. Kwon HT, Mayer JA, Walker KK, Yu H, Lewis EC, Belch GE. Promotion of frequent tanning sessions by indoor tanning facilities: two studies. J Am Acad Dermatol. 2002 May;46(5):700-5.

40. Demierre MF. Time for the national legislation of indoor tanning to protect minors. Arch Dermatol. 2003 Apr;139(4):520-4.

41. Karagas MR, Stannard VA, Mott LA, Slattery MJ, Spencer SK, Weinstock MA. Use of tanning devices and risk of basal cell and squamous cell skin cancers. J Natl Cancer Inst. 2002 Feb 6;94(3):224-6.

42. National Cancer Institute. Genetics of skin cancer. Melanoma [Internet]. Bethesda: National Cancer Institute [cited 2013 Mar 9]. Available from: http://www.cancer.gov/cancertopics/pdq/genetics/skin/HealthProfessional/page4.

43. Borland R, Hill D, Noy S. Being SunSmart: changes in community awareness and reported behaviour following a primary prevention program for skin cancer control. Behav Change. 1990;7:126-35.

44. MacKie RM. Incidence, risk factors and prevention of melanoma. Eur J Cancer. 1998;34(Suppl 3):S3-6.

45. Marks R. An overview of skin cancers. Incidence and causation. Cancer. 1995 Jan 15;75(2 Suppl):607-12.

46. Turner M. Sun safety: avoiding noonday sun, wearing protective clothing, and the use of sunscreen. J Natl Cancer Inst. 1998 Dec 16;90(24):1854-5

47. EyeCare America. Sunglasses [Internet]. San Francisco: EyeCare America; c2007 [cited 2012 Nov 22]. Available from: http://www.aao. org/eyecare/tmp/sunglasses.cfm.

48. Stern RS, Weinstein MC, Baker SG. Risk reduction for nonmelanoma skin cancer with childhood sunscreen use. Arch Dermatol. 1986 May;122(5):537-45.

49. Skin Cancer Foundation. Early detection and self exams [Internet]. New York: Skin Cancer Foundation [cited 2012 Nov 20]. Available from: http:/ www.skincancer.org/skin-cancer-information/early-detection.

50. Wender RC. Barriers to effective skin cancer detection. Cancer. 1995 Jan 15;75(2 Suppl):691-8.

51. Markovic SN, Erickson LA, Rao RD, Weenig RH, Pockaj BA, Bardia A, et al.; Melanoma Study Group of the Mayo Clinic Cancer Center. Malignant melanoma in the 21st century, part 1: epidemiology, risk factors, screening, prevention, and diagnosis. Mayo Clin Proc. 2007 Mar;82(3):364-80

52. Girgis A, Sanson-Fisher RW, Tripodi DA, Golding T. Evaluation of interventions to improve solar protection in primary schools. Health Educ Q. 1993 Summer;20(2):275-87. 
53. Bastuji-Garin S, Grob JJ, Grognard C, Grosjean F, Guillaume JC. Melanoma prevention: evaluation of a health education campaign for primary schools. Arch Dermatol. 1999 Aug;135(8):936-40.

54. Buller DB, Taylor AM, Buller MK, Powers PJ, Maloy JA, Beach BH. Evaluation of the Sunny Days, Healthy Ways sun safety curriculum for children in kindergarten through fifth grade. Pediatr Dermatol. 2006 Jul-Aug;23(4):321-9.

55. Buller DB, Reynolds KD, Yaroch A, Cutter GR, Hines JM, Geno CR, et al. Effects of the Sunny Days, Healthy Ways curriculum on students in grades 6 to 8. Am J Prev Med. 2006 Jan;30(1):13-22.
56. Buendía-Eisman A, Feriche-Fernández E, Muñoz-Negro JE, CabreraLeón A, Serrano-Ortega S. Evaluation of a school intervention program to modify sun exposure behaviour. Actas Dermosifiliogr. 2007 Jun;98(5):332-44. (In Spanish.)

57. Gilaberte Y, Alonso JP, Teruel MP, Granizo C, Gállego J. Evaluation of a health promotion intervention for skin cancer prevention in Spain: the SolSano program. Health Promot Int. 2008 Sep;23(3):209-19.

Received January 16, 2013 Accepted in revised form September 5, 2013 